This item was submitted to Loughborough's Research Repository by the author.

Items in Figshare are protected by copyright, with all rights reserved, unless otherwise indicated.

\title{
The impact of mobile technology on a UK police force and their knowledge
} sharing

PLEASE CITE THE PUBLISHED VERSION

PUBLISHER

(C) Information and Knowledge Management Society

VERSION

AM (Accepted Manuscript)

LICENCE

CC BY-NC-ND 4.0

\section{REPOSITORY RECORD}

Lindsay, Rachael, Louise Cooke, and Thomas Jackson. 2019. "The Impact of Mobile Technology on a UK Police Force and Their Knowledge Sharing”. figshare. https://hdl.handle.net/2134/5687. 
This item was submitted to Loughborough's Institutional Repository (https://dspace.lboro.ac.uk/) by the author and is made available under the following Creative Commons Licence conditions.

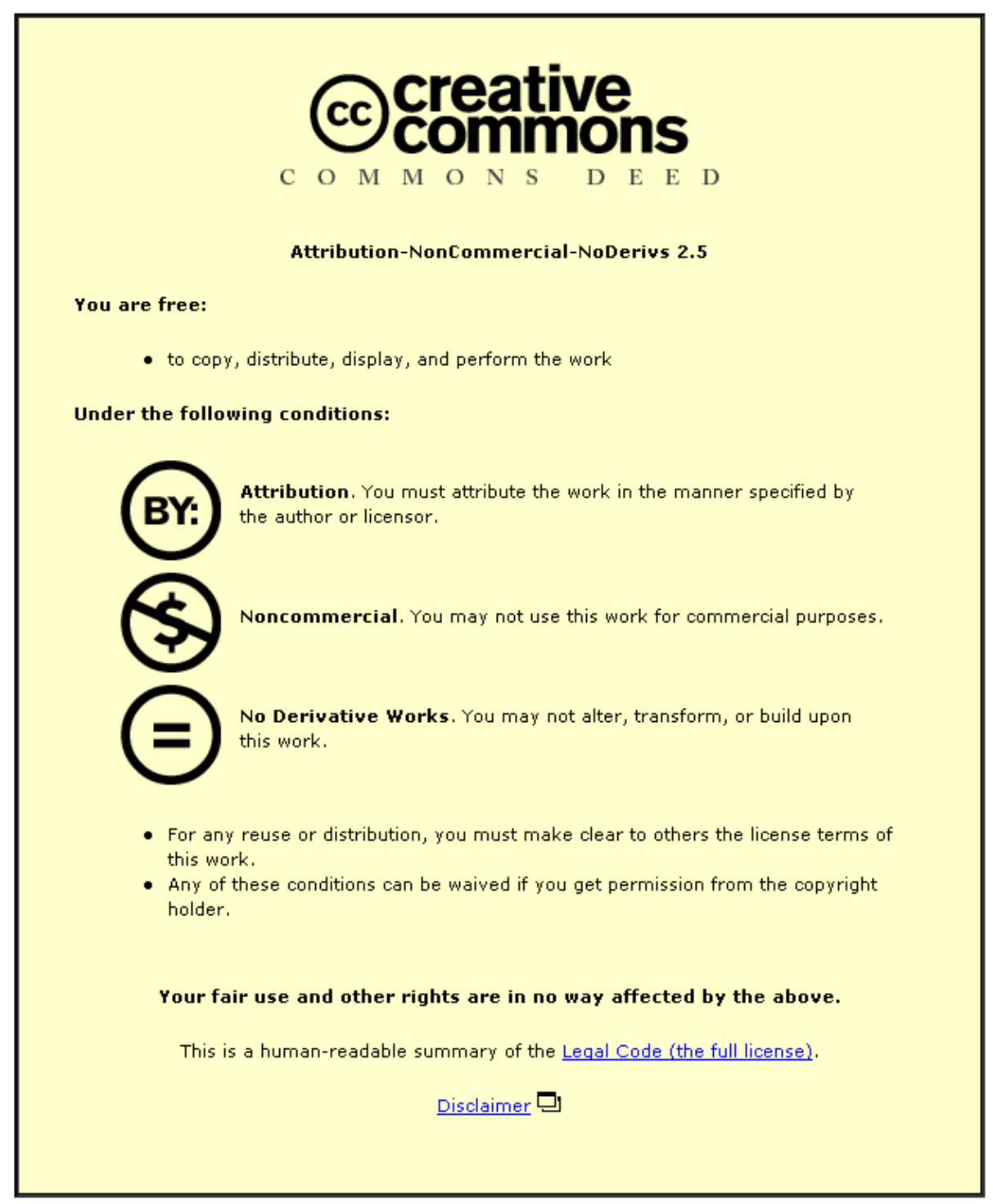

For the full text of this licence, please go to: http://creativecommons.org/licenses/by-nc-nd/2.5/ 
The Impact of Mobile Technology on a UK police force and their knowledge sharing

Rachael Lindsay, Louise Cooke and Tom Jackson.

Knowledge Management Research Group, Department of Information Science, Loughborough University, Loughborough, Leicestershire, LE11 3TU.

r.e.lindsay@lboro.ac.uk, l.cooke@lboro.ac.uk, t.w.jackson@lboro.ac.uk

Keywords: Mobile information and knowledge management, mobile technology, knowledge sharing, policing, practical implications. 


\title{
The Impact of Mobile Technology on a UK police force and their knowledge sharing
}

\begin{abstract}
.
The paper discusses an evaluation study that investigates the impact of mobile technology on a UK police force and on knowledge sharing processes. An empirical, ethnographic approach to the research was adopted, using a mixed method approach of focus groups, questionnaires, observational 'work shadowing' and interviews with a total of 42 staff involved in a trial of mobile technology. The findings from the various methods are consistent, suggesting that mobile technology has a positive impact on policing and knowledge sharing. The timeliness of information improved, increasing the availability of information for decision-making. Reductions in information overload were apparent due to mobile technology providing greater control over information. There was a positive impact on knowledge sharing in the course of operational duties. Information and knowledge could be shared more quickly with officers in the field; and mobile technology provided a new avenue for keeping each other up to date with events. The paper contributes towards an understanding of the upcoming concept of 'mobile knowledge management' and offers a set of recommendations to manage the possible long-term risk of mobile technology on knowledge sharing.
\end{abstract}

\section{Introduction}

Since the September $11^{\text {th }} 2001$ events in New York, policing organisations are increasingly realising the importance of sharing information and knowledge. It is no longer acceptable to hoard information in silos. Davenport and Prusak (2002) championed the economic arguments for knowledge integration and have shown that poor knowledge management practices have the potential to lead to high costs as a result of knowledge gaps and deficient decision-making. Jashapara (2004: 309) recognises the principal task of knowledge management is to 'systematically exploit and share human knowledge by using the appropriate technology and techniques in order to enhance organisational performance'. Knowledge work is contended by Brodeur \& Dupont (2006: 22) to be perceived as carrying little prestige within policing organisations, however policing is unquestionably a knowledgeintensive activity. Holgersson (2005) studied the practice of police officers and highlighted numerous situations where knowledge is required, such as identifying potential suspects, communicating with people, solving disputes and using information technology to collect and analyse information. Equally, 
the research findings of Luen and Al-Hawamdeh (2001: 318) establish that police officers come into contact with an astounding amount of information, suggesting a need for police to be proficient knowledge workers. Information is held in a variety of sources and formats. In the past police officers could only access this information at a police station, which presented issues including identification of the most efficient and timely manner to surface knowledge for problems and a potential for reduced visibility (Gottschalk, 2006a: 4). Knowledge management (KM) principles may be applied to overcome these problems. Policing is therefore an organisational context that is likely to achieve significant benefits from the application of technology and techniques to enhance knowledge management.

Recognition of evident bureaucracy within UK police forces has prompted recent media and political debate about the use of mobile information management in policing. A topical article by Arnott (2007) has suggested that police need more mobile information technology. This was instigated by a recommendation by the Chief Inspector of Constabulary, Sir Ronnie Flanagan, who is 'calling for more widespread use of mobile devices to cut the bureaucracy bedevilling UK Police' (Arnott, 2007), as such technology enables officers to input data directly into police force systems. Governmental drivers, including a recent investment of $£ 50$ million of public money into a mobile information technologies initiative for UK police forces (Public Technology, 2008a) has led to all UK police forces working towards the mobilisation of their information management systems. A further investment of $£ 25$ million is anticipated to deliver 30,000 extra devices for operational officers by March 2010 (Home Office, 2008). It has been estimated that mobilisation of information could save as much as $£ 800,000$ a year for the average police force (Mills, 2008), providing that forces implement them correctly in order to maximise their potential.

Such high-profile drivers and investment means it is important to identify, from a knowledge management perspective, the benefits of a mobile technology strategy on a UK police force. This paper will investigate the impact of implementing mobile technology into a UK police force. Recommendations are given in order to manage the risks of mobile technology with regards to policing and knowledge sharing. 


\section{Knowledge sharing and technology}

\subsection{Current knowledge sharing issues in policing}

Information and knowledge lie at the heart of most law enforcement activities. Academics have studied policing activities for the past 40 years and during this time research findings have challenged the notion that policing is primarily associated with patrolling the streets, as police officers must also gather intelligence (Wilson et al, 2001: 35). A police officer relies on information, gathered facts and tacit knowledge developed from street experience in order to draw conclusions. Sharing this knowledge effectively is now recognised as critical to effective crime prevention, reduction and investigation strategies (Gottschalk, 2007b: 193). Similarly, an empirical study by Glomseth et al (2007: 106) into the effect of knowledge sharing in police investigations within the Norwegian police force found that detectives must work together rather than in isolation to solve criminal cases such as terrorism, corruption and trafficking, thus knowledge sharing is critical in acquiring information for evidence in cases. However, policing organisations encounter significant barriers in effectively sharing knowledge. Claver et al (1999: 457) and Walker \& Katz (2005: 466) have argued that a bureaucratic culture is typical of public agencies because of the different activities they conduct and systems accessed (sometimes paper-based) in order to pursue a common goal. Similarly, White (2007: 128) suggests most policing organisations are organised in the same way, consisting of a hierarchical command structure and authoritarian management style. The majority of employees can be found at the bottom level of the hierarchy, which may make it difficult for senior managers to tap into the entire wealth of knowledge held at the lower level. This can cause the flow of information to break down, with a danger of hindering decision-making.

\subsection{The requirement for mobile technology in policing}

Technology has had a great influence on police practices and assisting in their knowledge related work (Colvin \& Goh, 2005; Techland, 1999). It is currently used to support policing in several ways, such as database systems to record crime details and geographic information systems to profile the characteristics of local policing environments, crime patterns and police performance to provide increased intelligence, as found by Ashby \& Longley's study (2005: 56) at Devon \& Cornwall Constabulary. Manning (1997: 362) notes that the introduction of two-way radios and mobile data terminals into patrol cars has increased the capacity to respond to crimes. Similarly, a research 
survey by Chan (2001: 156) of 506 Australian police officers identified that 72 per cent felt that information technology had made a great difference to police work and provided 'the capacity to follow a more problem-oriented style of policing'. Brown and Brudney (2003) concur that the effects of IT are favourable with regards to enabling benefits of a learning organisation, such as improving policing problem-solving abilities.

Mobilising information and knowledge processes of policing organisations grants police officers direct access to information previously accessed only by radio communications or by returning to a police station to use a desktop computer; where police officers can access information related to entities such as suspects, car registrations and warrants of arrest. It also allows them to record statements, view photographs and capture signatures and fingerprints electronically while on the go (Mills, 2008: 38). Consequently, the highly bureaucratic nature of policing may be altered, by reducing the need for lengthy paper-based processes and call operators to relay information. According to Home Office statistics, English and Welsh police officers spend 56 million hours a year filling in paperwork, resulting in only 14 per cent of an average officers' time being spent on patrol (Russel, 2007). It is not uncommon for officers to write details of individuals (e.g. addresses) approximately sixteen times (Public Technology, 2007b). Figure one represents the average amount of paperwork a police officer requires to conduct their daily duties.

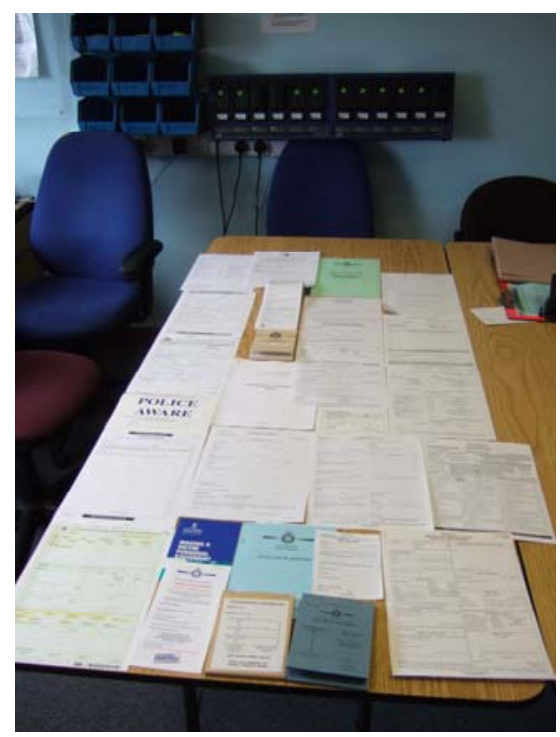

Figure 1: Average amount of paperwork for daily operations 
Despite there being many significant potential benefits to mobilisation, it may present risks to knowledge sharing. Research by Collier (2006) takes a negative stance with regard to the impact of technology in policing, suggesting that police officers rely more on tacit knowledge to complete their duties. Similarly Ng \& Ang (2007) argue that IT is itself insufficient to manage knowledge and turn their attention towards nurturing communities of practice (Wenger et al, 2001) for sharing tacit knowledge in order to enhance the learning of an organisation, as exemplified by the case in the Singapore Police Force. This notion of the role of social and organisational issues becoming threatened by technology is followed through in research by Edwards et al (2005) which found that the importance of informal knowledge sharing systems has not previously been recognised by policing organisations and that technology is perceived by some officers as a barrier to communication. Whilst the knowledge management literature recognises the value of information and knowledge sharing systems, there is a danger of these being undermined and this could become more apparent when mobile technology is implemented.

Norman \& Allen (2005: 204) investigated the initial impacts of the introduction of mobile information technologies into a UK police force and suggested there has been relative neglect in the literature on the potential opportunities and challenges posed by mobile information technologies; they recommend that ethnographic studies would help to extend and further explore issues identified within their study (2005: 224). This conception is to some extent addressed in related work by Agrawal et al (2003: 75), Nulden (2005) and Pica et al (2004), but it appears relatively little is known about how mobilising a policing information environment impacts on working practice and knowledge sharing processes. Vaast and Walsham (2005: 67) comment that we can be confident there is an impact from the introduction of ICT into the workplace but there is little understanding of how this affects working practices. Agrawal et al (2003) have conducted research into the impact of mobile information technology in police work, but their work is limited to studying the impact on officers in patrol cars; as usage increases throughout the force, it is likely to trigger further changes in working practices (Ibid.).

\subsection{Justification for the study}

The current impact of mobile technology given above has presented arguments for and against the introduction of technology in policing. This debate forms the driver and motivation for doing the ethnographic study whose findings are indicated below. There are significant benefits to be had from 
mobilising information and knowledge processes, including cost and time savings from completing extensive paperwork. The study seeks to investigate the impact of mobile technology so that issues from introducing mobile technology into a hierarchical organisation, such as a police force, can be minimised. This will contribute to ensuring that maximum value and benefits can be realised. In doing so, it seeks to close the gap in the literature recognised by Norman \& Allen (2005) (see section 2.2). The study will provide further data on the nature, use and issues affecting mobility.

\subsection{Main objectives of the study}

The main objective of the study is to investigate the impact of mobile technology on a UK police force and their knowledge sharing practices. The study will identify the opportunities and challenges offered by mobile technology. This will contribute towards the literature, which takes a mixed stance on the impact of mobile technology. Recommendations as to how the challenges of mobile technology can be managed will also be produced to maximise the benefits. Data for the study is provided through a two-week pilot study of mobile technology via an ethnographic approach. Further details of the study are given in section three.

\subsection{The mobile data terminal (MDT) solution}

Figures two and three show the MDT solution that is being trialled in a two-week pilot study within the Leicestershire Constabulary. The MDT solution is a Panasonic Toughbook, which is a ruggedised mobile laptop built to suit the needs of a tough policing environment. It has a reliable wireless connection for accessing information remotely (Panasonic, 2008). The MDT can be removed from its in-vehicle docking station and can be used out of the vehicle (e.g. in properties) as a portable device, allowing 'anytime anywhere' crime recording.
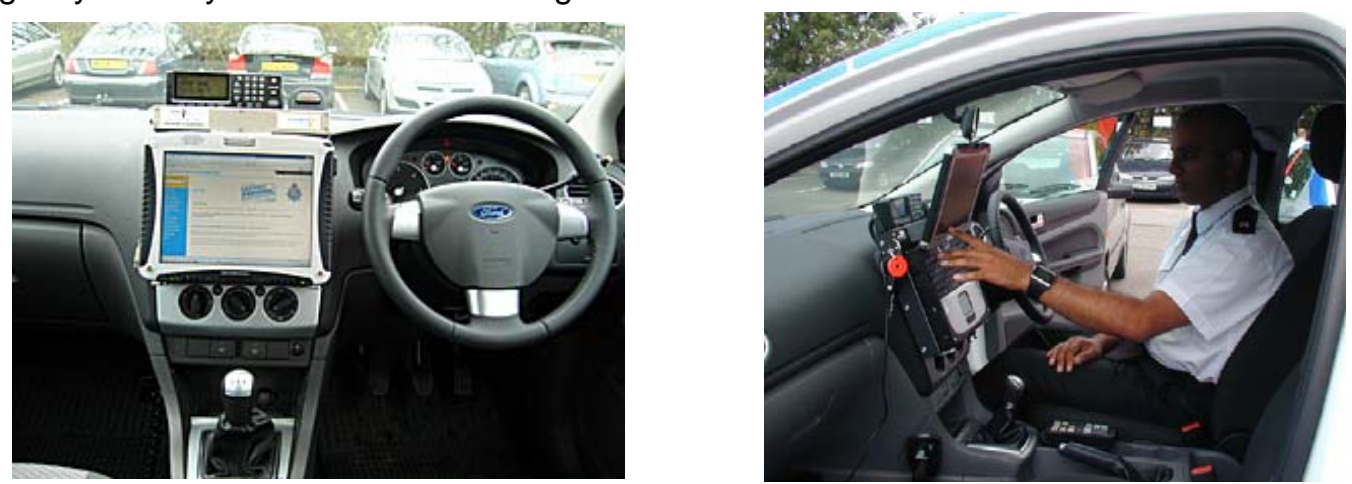

Figures 2 \& 3: The MDT solution in the Leicestershire Constabulary 


\section{Research Methods}

\subsection{Research strategy}

The Leicestershire Constabulary commissioned a team from a Department within a UK University to undertake a programme of evaluation of the pilot implementation of mobile data terminals (MDTs) in response vehicles. An inductive theory approach was taken because of lack of control over variables, such as the level of computer experience held by officers and the information systems used during the pilot. Employing an inductive theory strategy allowed an exploratory approach to the research where different aspects of the impact of technology can be investigated (Bryman, 2001: 10). The research followed an ethnographic design to allow in-depth exploration of the impact of mobile technology within the Leicestershire Constabulary. As an ethnographic approach was taken, the study has the advantage of regular interaction with the Constabulary and an intimate understanding of the organisational culture.

\subsection{Sampling Method}

The selection of the Leicestershire Constabulary for the research was based on convenience sampling, which is built on selections which suit the researcher and which are 'first to hand'. A good working relationship was established with senior management of the Leicestershire Constabulary. Although a convenience sampling technique can be recognised as hard to equate with good research (Denscombe, 2003: 17), it is believed that the organisational context of the Leicestershire Constabulary is one that fully meets the needs of the research. The Constabulary is taking an innovative approach to mobile technology. It is the first Force in the country to introduce mobile data terminals into police vehicles (BBC News, 2008) and the MDTs enable officers responding to incidents to have full mobile access to internal and external systems via the same interface available to them from their workplace desktop computer. Therefore, this approach is likely to see a greater impact on policing and knowledge sharing than approaches taken by other Forces, with mobile access to only email and calendar facilities.

\subsection{Data Acquisition}

A multi-method approach of focus groups, questionnaires, observation and interviews were adopted. Each method investigated the following: 
- the impact on work practice, the situations and processes that the officers used MDTs, and how they enhanced or hindered their work practices

- the main perceived risks and benefits of mobile technology, in terms of knowledge management.

\subsubsection{Focus group}

Eight semi-structured focus groups were held with a total of 30 operational police officers participating in the mobile technology pilot project. The groups took place before and at the end of the trial period. Each focus group had between three to six participants, a facilitator and an assistant. The focus groups provided a forum for open discussion, where the aim was to extract qualitative information and reach consensus regarding officers' experiences and perception of the impact of mobile technology. Data collected in the focus groups covered that mentioned in section 3.3.

\subsubsection{Questionnaire}

During the focus groups officers completed a total of 30 pre and 30 post-trial questionnaires to obtain quantitative information regarding the usage and perceptions of MDTs. The questionnaires enabled a profile to be built for each officer of their characteristics and attitudes towards mobile devices. Questionnaires allow the supply of pre-coded answers by employing a Likert scale. For example, such as how frequently MDTs were used. Standardised answers remove the scope for variation through face-to-face contact that is offered in interviews. This also reduces the likelihood of contaminating responses in the wording of the questions or the manner in which the question is asked (Cornford \& Smithson, 2006:70).

\subsubsection{Observation - 'work-shadowing'}

A total of 18 out of 30 officers who had been selected to participate in the pilot project were observed ('work-shadowed') during the two-week pilot period by a team of nine observers in order to evaluate the use of each MDT device. The work shadow exercise was conducted during a range of early, late, day and night shifts in order to explore the impact of mobile technology in a variety of situations. Observation allowed the researcher to investigate the actions and behaviour of people within natural circumstances, and provide useful insights; this can be used to complement interview, focus group 
and questionnaire data and may have less bias (Robson, 2002: 310). A total of 38 incidents were shadowed throughout the course of around 20 shifts. Data collected included how the MDT was used for the incident (e.g. recording incident details from the victim), whether the officer had to return to the station and why, the IT systems accessed via the MDT and any additional communication and recording incidents used for the incident (e.g. radio). The data was recorded via an observation sheet with tick boxes, one sheet for every incident attended where a MDT was used.

\subsubsection{Interviews with stakeholders}

In addition to operational police officers it was also important to analyse the impact of MDT use on a selection of stakeholders who are not directly involved in frontline duties. Therefore, semi-structured interviews were conducted in three groups with a total of 12 staff from the Call Management Centre to investigate the impact of the pilot project on their own work practices, in terms of benefits, challenges arising and future opportunities.

\section{Results and Discussion}

\subsection{Knowledge management benefits of mobile technology in policing}

\subsubsection{Decision-making via Information Systems}

Prior to the commencement of the pilot, the benefits that officers hoped to achieve from mobilisation related mainly to the provision of opportunities for better access to intelligence systems for decisionmaking whilst on duty, such as conducting stop checks, searching for missing persons and identifying suspects. These benefits appear to have been achieved in practice. The work shadow exercise indicated that MDTs improved the availability of information for decision-making purposes. They also helped to speed up business processes and improved the timeliness and accuracy of data held. During the pilot nearly half of MDT usage was for intelligence checks. A quarter of time was used for crime recording and the remaining main usage was related to identification purposes, updating relevant systems and obtaining information from the Intranet. Officers were able to update information systems on the move regardless of geographical location. Interview data from call management staff suggested that this capability reduced their workload, creating more time to focus on major incidents. Nearly all officers in the pre-trial focus groups anticipated that direct input of information would help to speed up business processes. Actual experience from observation findings showed that on average it 
took an officer 11 minutes to input details onto the crime and intelligence information management system, a dramatic reduction from the previous minimum of three days before full details of a crime are available. However, this was not apparent for all crimes recorded. Where statements from victims or witnesses were required, it was observed that the lack of an electronic signature facility meant that officers had to revert to using paper forms to take statements. Nevertheless, the apparent timeliness from direct input means that decisions are more likely to be robust, as timeliness is an innate characteristic of good quality information. This mirrors the experience of mobile technology users in the West Yorkshire Police to improve their decision-making (Allen \& Shoard, 2005). The usage of MDTs to access information and knowledge sources during the two-week pilot is reflected in Figure four:

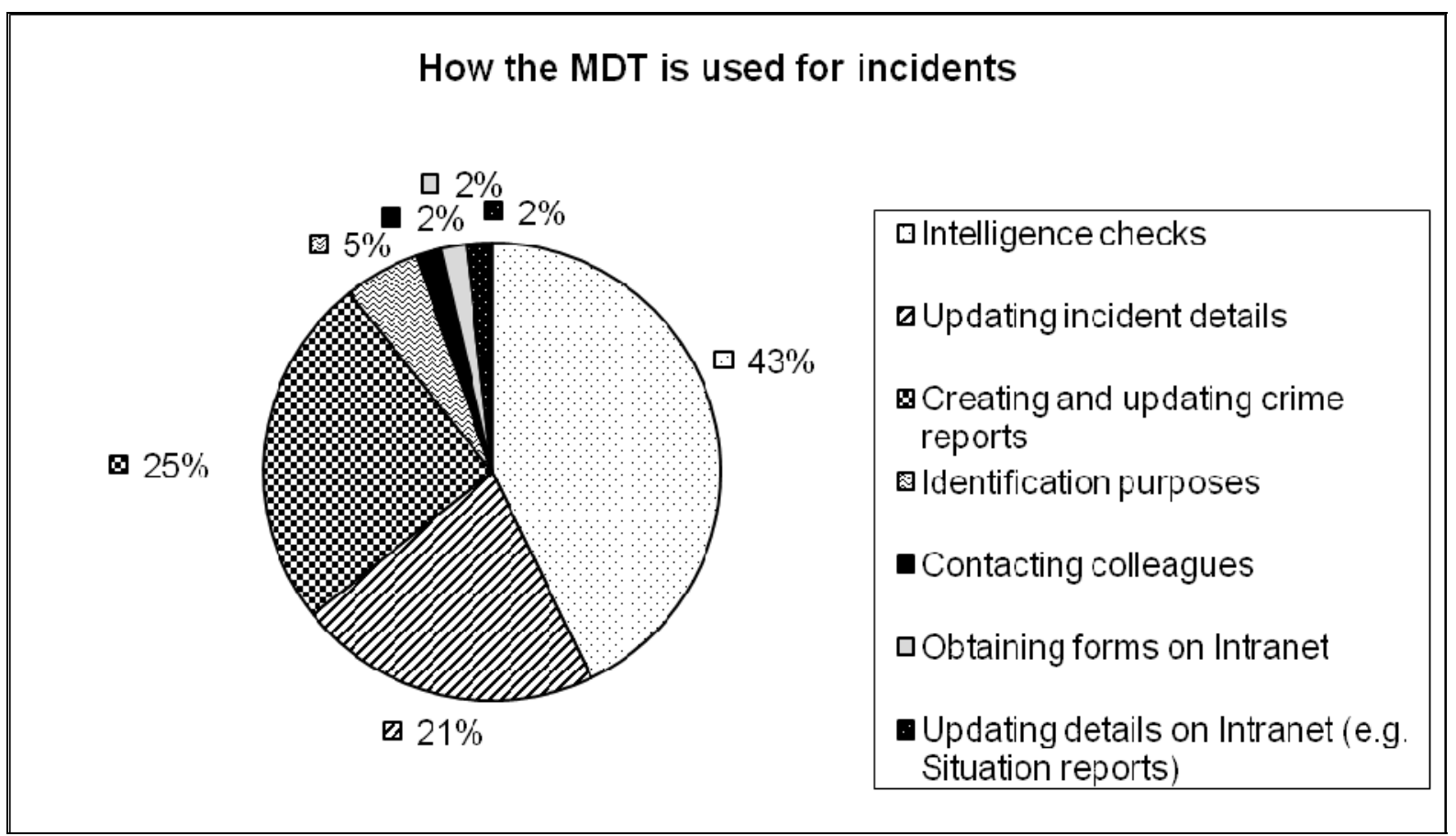

Figure 4: Usage of MDTs to access information and knowledge sources during two-week pilot

During the post-trial focus groups, on the whole participants noted that 'having their entire knowledge base (e.g. history, policies and law) at their fingertips' meant that they could make arrests and deal with incidents with greater confidence. This was seen particularly with regard to the immediacy and timeliness with which incidents could be dealt with. An example provided in one of the focus groups was an incident involving a shoplifter: the incident was recorded and filed, and the offender cautioned, within an hour, a process that the officer would normally expect to take five hours. An increased 
numbers of arrests had resulted from the additional access to information and real-time access to intelligence afforded by use of the MDT: in one incident, for example, this had enabled the connection between a previous and a current incident to be established, leading to an arrest. This finding is conformed by Norman \& Allen (2005: 213), who suggest that mobile technology allows officers to complete tasks better than without mobile technology, such as check several car registration numbers in the early hours of the morning. Gottschalk (2007b: 193) suggests that police officers are reliant on information and gathered facts to draw conclusions. Thus having the officers' knowledge base at their fingertips is beneficial to policing performance.

Before mobile technology, paper-based processes resulted in a loss of real-time intelligence. When a crime was registered onto the crime and intelligence information management system by the Crime Bureau, the crime number and a few details were visible on the system within hours but the record was not searchable. Mobile technology has granted officers access to more timely and detailed information and intelligence. For example, an arrest was made which would previously have been lost if officers had had to wait for information on the radio. This is echoed in findings by Allen and Shoard (2005), where the majority of survey respondents within the West Yorkshire Constabulary believed that mobile technology enabled them to keep themselves and their colleagues better informed. Furthermore, when an incident was reported prior to mobile technology, staff in the call management centre followed a dynamic threat and risk assessment process to highlight to officers via the radio important related knowledge, such as previous history and warning markers of specific persons or addresses. This knowledge is held within an information system, however officers were previously unable to access this explicit knowledge when on the streets. Since call management staff can be handling several incidents at once the old process held potential for important information relating to a particular incident to be missed. Mobile technology has overcome this issue by allowing officers to access directly important explicit knowledge held within information systems, regardless of geographical restrictions, thereby improving on the spot decision-making. This concept supports Von Guretzky's (2002) view of mobile knowledge management i.e. decision-making on the spot.

It was widely reported in the post-trial focus groups that the ability to access photographic identification reduced the potential for false arrests and increased the accuracy of stop checks. The 
bulk of post-trial focus group participants felt that they could take a more proactive approach to policing: they were able to monitor the incident management system and respond to jobs. They suggested that they were also able to communicate more effectively with the Control Room and to check whether incidents had been correctly recorded on the system. Reliance on the call management centre was reduced, as officers were able to view incidents and complete some checks themselves, rather than requesting information from the control room. In an example of a missing person enquiry, the officer could complete checks on their associates, which led to the missing person being located.

\subsubsection{Channels of communication}

Officers in the post-trial focus groups commonly reported that they made less use of the radio. They felt this reduced time delays in access to critical intelligence. In other incidents, officers only used the radio for an incident to request backup or to request directions en-route to an incident. This confirmed the perceptions of officers in the pre-trial focus groups, who suggested that they would become less reliant on the radio to obtain information. Call management centre staff concurred that MDTs may reduce the time needed to deal with an incident because there is less need to rely on the radio, which can sometimes have delays. For example, they proposed that during a murder investigation MDTs saved a large amount of information from being relayed over the radio. This suggests that mobile technology serves as an additional communication channel for officers, which has a lower level of latency for decision-making than using the radio. This finding may be paralleled with research by Agrawal et al (2003) and Norman and Allen (2005) into the impacts of mobile computing in a US and UK police department respectively, which identified a strong relationship between the level of communication and time available for officers due to a reduced need for the assistance of dispatch. This finding is 'a reflection of the usage of the email facility, which helps officers save time through effective communication without occupying the radio channel' (Agrawal et al, 2003: 86). In contrast, the post-trial questionnaire found that zero respondents made use of email and the majority made use of the radio or force information systems, with a small proportion (17 per cent of respondents) making use of face-to-face communication. Norman \& Allen (2005: 211) suggest that mobile technology complements existing communication channels rather than replaces it, as mobile technology can be used for lower priority requests for information that were otherwise obtained via the radio. In all cases 
of research, nearly all officers viewed this positively. Reduced latency created by mobile technology may have an additional positive upshot to officers in that they can also share information with other officers in the field more quickly (Norman \& Allen, 2005: 215).

\subsubsection{Management of Information}

Generally, officers anticipated being able to use their own judgement to select the relevant information for an incident rather than rely on that provided by a third party, which can lead to the provision of less critical or too much information. The majority of officers in the pre-trial focus group felt that this would allow them to have better control over the information available to them and to prioritise important communications: at present they may be overloaded with relatively unimportant information by the time they return to the station and check their inbox. Interviews with call management centre staff confirmed these perceptions. They suggested that the introduction of mobile technology had removed some of the difficulties in deciding what intelligence to share with officers responding to incidents: officers were now able to access intelligence directly, and to select or filter information using their own judgement. It was stated by one interview participant that officers could now view 'what they want, when they want', rather than waiting on call centre staff for information. They also advocated that mobile technology had reduced the need to repeat information over the radio, as officers now have the full information recorded in front of them. In the post-trial focus groups it was found that officers liked the ability to view the full details of an incident, rather than brief details obtained via the radio. Although the notion of information overload being exacerbated by advances in information and communication technologies is recognised by Edmunds and Morris (2000), it has only been explored to a limited extent by Allen \& Shoard (2005), who suggest that mobile technology assists in spreading the load of information. Syson (2007) proposes that mobile technology is a more effective tool to share information than the verbal and paper-based systems used in policing, as it provides constant access to recorded information.

Prior to the trial, some officers felt that data quality would be compromised, as the current checking processes carried out by the Crime Bureau would be bypassed. However, the majority of officers in the preliminary focus groups perceived that data quality would improve, as crime reports could be created without delay. During the two-week pilot, the impact on the quality of information was also 
enhanced with 82 per cent of crime reports inputted using mobile technology having no data quality issues.

\subsubsection{Impact on Knowledge sharing}

With regards to Nonaka et al's SECI model (2000), on the whole officers in the pre-trial focus groups felt that knowledge sharing between officers would improve as a result of use of mobile technology: all officers agreed that MDTs provided a new avenue for keeping each other up-to-date with events. The work shadow exercise observed instances during the pilot where officers with a MDT completed checks for other colleagues and shared history and warning markers over the radio, enabling nonmobile technology enabled officers also to benefit from mobile technology by becoming better informed. Officers in the post-trial focus groups reported similar findings. This may improve knowledge sharing at the combination stage of the SECI model (Ibid.). A small number of pre-trial participants suggested that in the long-term, interpersonal contact might improve, as officers will be able to complete administrative tasks whilst on duty. They suggested they would therefore have more free time to share experiences and information with colleagues when they return to the station, thus improving the level of socialisation. It is important to note, however, that all officers did not share this view. Some pre-trial participants felt that opportunities for informal interaction would be seriously curtailed as a result of the use of MDTs. This was also highlighted as an important risk in the post-trial focus groups, where a number of officers identified increased isolation, reduced team spirit, less effective knowledge-sharing and loss of morale, as face-to-face contact with colleagues is reduced. They highlighted the importance of continuing with face-to-face briefings in order to promote a positive shift culture and to maintain effective intelligence gathering. An increase in double crewing would also contribute to reducing isolation. In contrast, no survey respondents in the West Yorkshire Constabulary believed that mobile technology had taken the place of face-to-face meeting opportunities, although the level of face-to-face communication had already been reduced by the widespread use of email (Allen \& Shoard, 2005). Despite the risk of isolation, the observation of the work-shadow exercise indicated that during the trial itself, most officers reacted in a positive manner to being able to stay out of the station and therefore attend more incidents. The post-trial questionnaire found that zero respondents made use of email and the majority made use of the radio or force information systems, with a small proportion (17 per cent of respondents) making use of faceto-face communication. This suggests that opportunities for informal knowledge sharing remain with 
mobile technology. Similarly, Norman \& Allen (2005) find that despite the introduction of mobile technology, officers still chatted among themselves in the office and there was a good level of team spirit.

However, in the long-term changes to communication and work patterns as a result of mobile technology may result in a potential loss of important salient knowledge acquired via the radio whilst completing other tasks (e.g. 'warning markers). Officers in other UK police forces have expressed similar concerns that 'there will be a loss of incidental knowledge as a result of the transfer to a more personal information environment'. Information will be sent to an individual officer in accordance with their role or availability so knowledge will be only shared directly to particular officers rather than "by virtue of coming over the voice radio system' (Norman \& Allen, 2005: 216).

\subsection{Recommendations}

There is a potential danger that mobile technology may lead to specific tacit knowledge becoming isolated amongst a few officers, as officers begin to spend less time in the station. In order to at least preserve knowledge sharing, the following recommendations have been made which may be of benefit to similar types of organisations using or about to implement mobile technology:

1. Although organisations have to cut costs, they should still provide enough time so officers can discuss work and social events face-to-face. A reduction in the time spent in stations could lead to a loss of team spirit and morale, or a reduction in formal and informal exchange of information, knowledge and intelligence.

2. To overcome the risk of isolation it is recommended that senior management implement a long-term initiative to create a knowledge culture.

a. To encourage a knowledge culture an open-plan environment with breakout areas and other informal meeting amenities should be placed into all of the Constabulary's operational premises, for example staff canteens. This provides officers with an opportunity to informally discuss work related experiences during breaks and pass on their tacit knowledge to other officers across the organisation.

b. Other mechanisms to encourage a knowledge culture might include the continued use of face-to-face briefings; regular use of double crewing and encouragement to 
meet informally during refreshment breaks or in organised social and team-building events.

In order to improve the performance of MDTs, it is recommended that specific technical issues that were common in the observation and post-trial focus groups be addressed. To do so, the following recommendations are made:

3. Not all details could be recorded electronically due to the lack of an electronic signature facility. A critical feature that would incur significant efficiency gains is the provision of an electronic signature function acceptable to the Criminal Justice Services, which is date and time-stamped to provide an audit trail.

4. During some work-shadowing exercises, it was found that officers could not log onto the MDT at the start of the shift because the previous user had not logged out correctly. The importance and process of logging off correctly needs to be emphasised as part of user training. However, training should not just address technical use of equipment, but should also cover changes in new communication and work protocols, and relevant health and safety practices. Any additional systems to be made available via the MDTs should be accompanied by appropriate training in their use.

5. Post-trial evaluation found that concerns were raised relating to health and safety and ergonomics: for example, the positioning in the vehicles meant that officers were knocking their knuckles on the docking station when using the indicator. The integrated keyboard was identified as being too small and therefore awkward to use. On the other hand, the USB keyboard did not fit easily into the glove compartment and whilst it was stowed in the compartment, keys were inadvertently pressed causing blank records to be submitted. It was pointed out by a number of participants that an illuminated keyboard would be useful, as would a wireless keyboard that obviated the need to have trailing cables. This is recommended along with a more flexible screen solution that allows for pivoting towards the driver for greater comfort and protection of sensitive information when a rear-seat passenger is in the police vehicle, 


\subsubsection{The Applicability of the Recommendations}

To determine the applicability of the recommendations, an interview was held with the acting Chief Superintendent. The Chief Superintendent is responsible for the overall program that incorporates the mobile information project within the Constabulary. During the interview, the first recommendation was fully accepted by the Chief Superintendent, who strongly acknowledged the need to retain start of shift and post shift briefings and maintain a level of face-to-face contact between officers. The proposal to encourage a knowledge culture through an open plan environment was recognised by the Chief Superintendent. He suggested that the Constabulary already encourage this to some extent and are seeking to provide more informal meeting amenities in their Strategic Estates review as a result of recommendation 2a. The Chief Superintendent expressed a clear understanding of the issue of isolation, and consequently actions will be taken to encourage a balance between increasing the level of police visibility and maintaining face-to-face contact. For example, limiting the number of times officers return to the station from after each incident to during meal and refreshment breaks and at the end of the shift; along with the actions suggested in recommendation $2 \mathrm{~b}$.

\subsubsection{Practical Implications}

The implementation of mobile technology is likely to have significant impact on the current working practice of the Constabulary, For example, shift patterns are likely to change as a result of reductions of shift time spent in the station and greater time spent on patrol. In terms of crewing arrangements, mobile technology may conflict with the existing policing strategy to deploy single crewed officers to achieve higher visibility levels. The study has found that the use of MDTs whilst single crewed appears to be impractical, as officers did not have time to complete the full range of checks prior to attending incidents. They had to resist the temptation to view information on the MDT whilst driving. They were also not able to use the MDTs to check intelligence when attending grade one incidents. Consequently, the continued use of double crewing is important in order to maximise the benefits to be had from MDTs and to minimise the impact on officer isolation. More importantly, the study has shown that mobile technology carries significant practical implications for existing business processes, such as the crime recording process and allocation of incidents. Crimes can now be recorded directly onto the crime recording system, which bypasses the need for crime input personnel. Officers can view incidents on the operational intelligence system, reducing the need for 
incidents to be dispatched via the radio. There is potential for job losses as a result of this but there are significant efficiency gains to be had as a result of the changes to the business processes.

In terms of the implications of the research findings for the wider target audience, other police forces can apply the lessons learned from the study. By doing so they may be able to minimise the risks, such as isolation and technical issues, to ensure that their deployment of mobile technology provides maximum business benefits and thus public funding is spent wisely. The lessons can also be applied to other non-policing organisations that are looking to invest in mobile technology.

\section{Conclusion}

The paper has explored, from a knowledge management perspective, the impact of mobilising technology on a UK police force and its effect on knowledge sharing by using a qualitative ethnographic approach. The small numbers of current studies within this area are still relatively underdeveloped in terms of theoretical learning. This research has brought together practical findings with a theoretical underpinning and to address findings in a specific context.

Despite the results not being widely generalisable to other contexts, as the Leicestershire Constabulary has taken an innovative approach to mobile technology, they still contain some interesting outcomes. Overall, mobile technology has had a positive impact on policing and knowledge sharing. The findings from the various evaluation elements are consistent and indicate that officers and call management centre staff who participated in the pilot were positive about the opportunities and benefits offered by the use of MDTs. The benefits to the Constabulary include a reduction in the amount of time to perform routine tasks resulting in fewer returns to the station, better time management and increased visibility; during the pilot officers were visible to the public for 97 per cent of the time shadowed. Overall this may be seen as an improvement to the policing performance provided.

Benefits to knowledge sharing are apparent from the findings. Firstly there was an improvement in the timeliness and accuracy of information meaning greater availability of information for decision-making purposes. It took officers eleven minutes to input information using mobile technology rather than the 
previous three days with the paper-based crime recording system. The impact on the quality of information was also enhanced with 82 per cent of crime reports inputted using mobile technology having no data quality issues. This provided better quality information to be shared among officers and other Forces. In addition, the delivery of knowledge to officers regardless of geographical restrictions meant that officers could make decisions with greater confidence. This may contribute to the concept of a learning organisation and support the upcoming concept of mobile knowledge management. Secondly, officers had better control over information and knowledge available to them as a result of mobile technology, rather than receiving too much or less critical information from the call management centre. Thirdly, it was found that since mobile technology has a lower level of latency than audio information (e.g. radio) officers could share information with other officers in the field more quickly. Finally, officers in the pilot believed that knowledge sharing had improved because mobile technology provided a new avenue for keeping each other up to date with events e.g. completing checks for other colleagues and sharing warning and history markers with non mobile technology users.

However, the positive findings of mobile technology on knowledge sharing only reflect the outcome of a two-week time period. Other research studies (e.g. Collier, 2006; Ng \& Ang, 2007; Edwards, 2005; Northrop, 1990a) suggest that mobile technology can have a negative impact on knowledge sharing and reduce opportunities for the informal exchange of knowledge and intelligence. This is important because previous research has found that the more knowledge that is shared between officers, the better the results of an investigation (Glomseth et al, 2007). A reduction in opportunities for knowledge sharing may be detrimental to the performance of the Constabulary and to the safety of the public. Overall, the benefits afforded by the use of mobile technology appear to outweigh the risks. Provided that the risks are recognised and managed by policing organisations in the long term, mobile technology will continue to improve the performance of policing and knowledge sharing. Further research is planned to investigate whether mobile technology increases or decreases the level of knowledge sharing, by speaking with officers at different levels of the organisation. Future research will also address the potential risk of knowledge sharing in light of the introduction of mobile technology. 


\section{References}

Agrawal, M., et al., 2003. Impact of mobile computing terminals in police work. Journal of Organisational Computing and Electronic Commerce, 13(2), 73-89.

Allen, D. K. \& Shoard, M., 2005. Spreading the load: mobile information and communication technologies and their effect on information overload. Information Research, 10(2), paper 227 [available at: http://informationr.net/ir/10-2/paper227.html].

Arnott, S., 2007, Police need more mobile IT, Computing, 12 September, [online], <http://www.computing.co.uk/computing/news/2198497/police-mobile>, [accessed 08.11.07].

Ashby, D. I. \& Longley, P. A., 2005. Geocomputation, geodemographics and resource allocation of local policing. Transactions in GIS, 9(1), 53-72.

BBC News, 2008. "First to get police laptops", [online], <http://news.bbc.co.uk/1/hi/england/7547549.stm>, [accessed 10.10.08].

Brodeur, J. \& Dupont, B., 2006. Knowledge workers or 'knowledge' workers? Policing \& Society, 16(1), 7-26.

Brown, M. M. \& Brudney, J. L., 2003. Learning organisations in the public sector - a study of police agencies employing information and technology to advance knowledge. Public Administration Review, 63(1), 30-42.

Bryman, A., 2001. Social research methods. Oxford: Oxford University Press.

Chan, J. B. L., 2001. The technological game: how information technology is transforming police practice. Criminology and Criminal Justice, 1(2), 129-159. 
Claver, E. et al., 1999. Public administration: from bureaucratic culture to citizen-oriented culture. International Journal of Public Sector Management, 12(5), 455-464.

Collier, P. M., 2006. Policing and the intelligent application of knowledge. Public Money \& Management, 26(2), 109-116.

Colvin, C. A. \& Goh, A., 2005. Validation of the technology acceptance model for police. Journal of Criminal Justice, 33, 89-95.

Cornford, T. \& Smithson, S., 2006. Project research in information systems. Basingstoke: Palgrave Macmillan.

Davenport. T. H. \& Prusak, L., 2000. Working knowledge: how organisations manage what they know. New York, McGraw-Hill.

Denscombe, M., 2003. The good research guide for small-scale social research projects.

Maidenhead: Open-University Press/ McGraw Hill,

Edmunds, A. \& Morris, A., 2000. The problem of information overload in business organisations: a review of the literature. International Journal of Information Management, 20(1), 17-28.

Edwards, J. S., 2005. Knowledge management systems: finding a way with technology. Journal of Knowledge Management, 9(1), 113-125.

Gottschalk, P., 2006a. Knowledge management systems in law enforcement: technologies and techniques. London: Idea Group.

Gottschalk, P., 2007b. Information systems in police knowledge management. Electronic Government: an International Journal, 4 (2), 191-203. 
Glomseth, R., et al., 2007. Occupational culture as a determinant of knowledge sharing and performance in police investigations. International Journal of the Sociology of Law, 35, 96-106.

Home Office - Police (2008) "The Policing Green Paper - from the neighbourhood to the national: policing our communities together" [online], <http://police.homeoffice.gov.uk/publications/policereform/policing_Green.pdf?view=Binary>, [accessed 21.07.08].

Jashapara, A., 2004. Knowledge management: an integrated approach. Harlow: Pearson Education.

Luen, T. W. \& Al-Hawamdeh, S., 2001. Knowledge management in the public sector: principles and practices in police work. Journal of Information Science, 27 (5), 311-318.

Manning, P. K., 1997. Information technologies and the police. Crime and Justice, 15, 349-398.

Mills, R., 2008. 'Ello, 'ello... it's the iPlod', Daily Express, $23^{\text {rd }}$ February, p. 38.

Ng, P. T. \& Ang, H. S., 2007. Managing knowledge through communities of practice: the case of the Singapore Police Force. International Journal of Knowledge Management Studies, 1(3-4), 356-367.

Nonaka, I., Toyama, R. \& Konno, N., 2000. SECl, ba and leadership: a unified model of dynamic knowledge creation. Long range planning, 33, 5-34.

Norman, A. \& Allen, D., 2005. Deployment and use of mobile information systems: a case study of police work. International Federation for Information Processing, 191, 204.

Northrop, A., et al., 1990a. Payoffs from computerisation: lessons learned over time. Public Administration Review, 50(5), 505-514. 
Nulden, U., 2005. Police patrol mobility: abstract of paper presented at the Case Western Workshop on Ubiquitous Computing, 24-26 October 2003.

$<$ http://weatherhead.case.edu/pervasive/participants_one.htm>, [accessed 11.06.08].

Panasonic (2008). "Law enforcement mobile data solutions". [online].

$<$ http://www.panasonic.com/business/Toughbook/law-enforcement-mobile-data-so.asp>, $\quad 2008$, [accessed 21.07.08].

Pica, D., et al., 2004. On mobility and context of work: exploring mobile police work. In: $37^{\text {th }}$ Hawaii International Conference on System Sciences (HICSS-37), Sprague, R. (ed.), Big Island Hawaii.

Public Technology, 2008a. "Police get 50 million funding for handheld computers", [online], $<$ http://www.publictechnology.net/modules.php?op=modload\&name=News\&file=article\&sid=15900>, [accessed 01.09.08].

Public Technology, 2007b. "Cheshire Police gets mobile data technology to improve front-line policing", [online],

$<$ http://www.publictechnology.net/modules.php?op=modload\&name=News\&file=article\&sid=11825>, [accessed 09.06.08]

Robson, C., 2002. Real world research: a resource for social scientists and practitioner-researchers. Oxford: Blackwell.

Russel, B., 2007. "Lib dems close ranks over Campbell leadership", The Independent, 17 May, [online], <http://www.independent.co.uk/news/uk/politics/lib-dems-close-ranks-over-campbellleadership-449157.html>, [accessed 09.06.08].

Syson, H., 2007. Knowledge sharing in the UK police service - a research study, MSc dissertation, Loughborough University, United Kingdom. datavetenskap, Linköping University, Sweden. 
Techland, 1999. "FACSys case study - Leicestershire Constabulary: FACSys makes history in fighting crime and improving public quality of life" [online],

$<$ http://www.techland.co.uk/index/facsys_case_leics>, [accessed 01.09.07].

Vaast, E. \& Walsham, G., 2005. Representations and actions: the transformations of work practices within IT use. Information and Organisation, 15(1), 65-89.

von Guretzky, B., 2002. "Mobiles Wissensmanagement. Technical report" [online], $<$ http://www.c-o-k.de/cp artikel.htm?artikel id=83>, [accessed 07.11.07].

Walker, S. \& Katz, C., 2005. The police in America: an introduction. New York: McGraw Hill.

White, M. D., 2007. Current issues and controversies in policing. Boston, MA: Pearson Education.

Wilson, D., et al., 2001. What everyone in Britain should know about the police. London: Blackstone. 